\title{
Comparação de Sistemas de Avaliação de Dietas para Bovinos no Modelo de Produção Intensiva de Carne. Confinamento de Tourinhos Jovens ${ }^{1}$
}

\author{
Alexandre Amstalden Moraes Sampaio², Rodolfo Marques de Brito ${ }^{3}$, Ricardo de Moraes Carvalho 4
}

RESUMO - Trinta tourinhos $3 / 4$ Canchim + 1/4 Nelore com 15 meses de idade e peso corporal médio de $417 \mathrm{~kg}$ foram confinados durante 84 dias. Os animais foram alimentados com rações compostas por silagem de milho, milho, farelo de algodão, farelo de soja, soja integral e mistural mineral, ajustadas segundo as recomendações do Sistema de Proteína Metabolizável (MP), do Sistema de Proteína e Carboidratos Líquidos de Cornell (CNCPS) e do Sistema de Proteína Digestível no Intestino (PDI), para ganho de peso corporal previsto de 1,3 kg/cab/dia. O ganho diário de peso corporal não diferiu entre os tratamentos CNCPS, MP e PDI, com médias de 1,48; 1,51; e 1,13 $\mathrm{kg} / \mathrm{cab}$, respectivamente. A análise econômica revelou lucro líquido de R \$116,25; R \$148,30; e R \$108,51/cab, para os sistemas CNCPS, MP e PDI, respectivamente. As dietas ajustadas pelos sistemas CNCPS e MP proporcionaram desempenho animal superior ao esperado, enquanto a dieta ajustada pelo sistema PDI não possibilitou o ganho de peso preconizado.

Palavras-chave: bovinos, farelo de algodão, soja, requerimentos, silagem de milho

\section{Comparison of Diet Evaluation Systems for Cattle in an Intensive Beef Production Model. Feedlot of Young Bulls}

\begin{abstract}
Thirty $3 / 4$ Canchim + 1/4 Nelore young bulls with $417 \mathrm{~kg}$ of body weight and 15 months of age, were confined during 84 days. The animals were fed with diets composed with corn silage, corn grain, cottonseed meal, soybean meal, whole soybean and mineral mix, adjusted in agreement with the recommendations of the Metabolizable Protein System (MP), Cornell Net Carbohydrate and Protein System (CNCPS) and Intestine Digestible Protein System (PDI), for predicted body weight gain of $1.3 \mathrm{~kg} / \mathrm{head} / \mathrm{day}$. The daily body weight gain did not differ among treatments CNCPS, MP and PDI, with $1.51 ; 1.48$; and $1.13 \mathrm{~kg} /$ head, respectively. The economic analysis revealed net profit of $\mathrm{R} \$ 116.25 ; \mathrm{R} \$ 148.30$; and $\mathrm{R} \$ 108.51 /$ head for CNCPS, MP and PDI systems, respectively. The diets adjusted by CNCPS and MP systems provided superior animal performance than that expected, while the diet adjusted by PDI system did not allow the predicted body weight gain.
\end{abstract}

Key Words: beef cattle, corn silage, cottonseed meal, requirements, soybean meal

\section{Introdução}

No Brasil, o confinamento de bovinos para corte é uma das técnicas mais utilizadas dentro da cadeia de produção da carne bovina, que, por sua vez, desempenha importante papel no processo de desenvolvimento socioeconômico, como supridora de alimento nobre para a população, matéria-prima para a indústria e na geração de divisas por meio das exportações (Martin, 1987). Entretanto, o desenvolvimento dessa atividade ainda requer a obtenção de melhores índices zootécnicos, principalmente frente à falta de uma política agropecuária adequada e ao incipiente conhecimento científico. Para minimizar esses problemas, a prática do confinamento tem procurado encurtar o tempo necessário para abate do animal e assim reduzir o ciclo produtivo, o que resultaria numa maior velocidade de entrada/saída de capital, por meio da engorda de animais jovens e com potencial genético para equilibrar a intensa modernização técnica exigida pela atividade.

É de grande importância a qualidade do animal num confinamento comercial. Os bovinos jovens e mestiços apresentam melhor eficiência na conversão alimentar, com maior impulso de crescimento e taxas progressivas de ganho (Arrigoni, 1995). Caso os ingredientes da ração tenham preços mais elevados, ou seja, de baixa a média qualidade, o lucro líquido só passa a ser superior em ganhos de peso maiores (Alleoni et al., 1980; Sampaio et al., 1995), que podem ser proporcionados por animais jovens. A raça Canchim, bem como seus mestiços, possui rusticidade,

\footnotetext{
1 Pesquisa financiada pela Fapesp (processo no 97/06792-1)

2 Zootecnista. Prof. Adjunto Depto. Zootecnia - FCAV/UNESP Jaboticabal (SP) - v.a. Prof. Paulo D. Castellane s/n - CEP: $14884-900$. Fone: 0-xx-16 3209-2684 /2685 / 2686 -Bolsista CNPq. E.mail: sampaio@fcav.unesp.br

3 Zootecnista. Pós-graduando (Doutorado) em Zootecnia FCAV. Bolsista Fapesp. E.mail: rmbrito@fcav.unesp.br

4 Zootecnista FCAV/Unesp.
} 
precocidade e alto rendimento na produção de carne (Vasconcelos, 1993). Além disso, tem apresentado excelente desempenho em provas de ganho de peso (Razook et al., 1984).

O sucesso na produção do novilho jovem depende da interação de uma série de fatores. Como a alimentação representa até $75 \%$ dos custos de produção no confinamento (Vasconcelos, 1993), o ajuste da dieta aos requerimentos do animal exigiu inúmeras pesquisas, que resultaram na elaboração de sistemas de nutrição, como o PDI (Jarrige, 1990), o CNCPS (Fox et al., 1992), e o MP (AFRC, 1993).

As recomendações nutricionais também procuraram promover eficiente fermentação no ambiente ruminal, mas basearam-se em condições de produção diferentes daquelas encontradas no Brasil. Por isso, é importante conhecer o sistema que demonstra melhor resposta à predição, em função das exigências e produções esperadas nos diversos sistemas de produção nacionais. Nesta perspectiva, Lanna et al. (1994) e Morais et al. (1996) conduziram trabalhos que objetivaram avaliar a predição do desempenho animal de acordo com a estimativa de requerimentos e ajuste de dietas. Os primeiros observaram ganho de $1,24 \mathrm{~kg} / \mathrm{cab} /$ dia em dieta ajustada pelo CNCPS para ganho de 1,04 kg/cab/dia em animais Nelore/Canchim de 10 meses e $225 \mathrm{~kg}$ de peso corporal.

Entre os alimentos mais utilizados para os bovinos confinados no Brasil está a silagem de milho, um volumoso de boa qualidade (Perry, 1980). Os alimentos concentrados incluem o milho, o farelo de soja (boa fonte de proteína de alta degradabilidade), o farelo de algodão (fonte de peptídeos e proteína bypass) e a soja integral (fonte protéica de preço mais acessível que o farelo desengordurado).

Magliocca et al. (1994) utilizaram silagem de milho, milho e farelo de soja em cruzados taurino/ zebuíno de $248 \mathrm{~kg}$ de peso corporal e registraram ganho de $1,31 \mathrm{~kg} / \mathrm{cab} / \mathrm{dia}$. Cruz et al. (1996) estudaram desempenho em confinamento de vários $\mathrm{F} 1$ (Nelore/Taurino), de $284 \mathrm{~kg}$ de peso e 15 meses de idade, com dieta semelhante, e observaram ganho de $1,47 \mathrm{~kg} / \mathrm{cab} /$ dia.

Nos trabalhos consultados, a elevada inclusão da soja integral em dietas para bovinos confinados está associada à obtenção de ganhos ao redor de $1 \mathrm{~kg} / \mathrm{cab} /$ dia, quase sempre associados a baixo consumo, como verificaram Obeid et al. (1980), Coutinho Filho et al. (1987), Sampaio et al. (1995) e Arrigoni (1995), que registraram ganhos de peso de 1,08; 1,10;0,97; e 1,06 $\mathrm{kg} /$ animal/dia, respectivamente. Utilizando farelo de algodão e trabalhando com animais de idade entre $18 \mathrm{e}$ 24 meses e peso corporal entre 251 e $304 \mathrm{~kg}$, Moura et al. (1975), Boin et al. (1977), Salomoni et al. (1980) e Coutinho Filho etal. (1995) observaram 1,10;0,91;0,88; e $0,70 \mathrm{~kg} / \mathrm{cab} /$ dia para ganho de peso, respectivamente.

O objetivo do presente trabalho foi avaliar o efeito da alimentação recomendada por diferentes sistemas de nutrição de ruminantes (MP, CNCPS, PDI) no desempenho de bovinos jovens confinados, em condições tipicamente nacionais.

\section{Material e Métodos}

Foram conduzidos, em períodos distintos, dois ensaios de desempenho em confinamento, utilizandose 15 baias de piso em concreto $\left(16 \mathrm{~m}^{2} /\right.$ baia $)$, com bebedouro servindo cada duas baias e cocho coberto. Em cada ensaio, foram utilizados 15 bovinos machos inteiros, 3/4 Canchim + 1/4 Nelore, com média de idade de 16 meses e apresentando, ao início dos respectivos ensaios, peso corporal médio de 411 (ensaio 1) e $423 \mathrm{~kg}$ (ensaio 2), alojados individualmente nas baias e distribuídos nos tratamentos de acordo com o peso corporal inicial.

Nos dois experimentos, os animais foram previamente alimentados durante 60 dias, visando a adaptação aos alimentos, homogeneização da condição corporal e redução dos efeitos de ganho compensatório. Foram estabelecidos três tratamentos, representados por dietas ajustadas de acordo com as recomendações de três sistemas (CNCPS, MP e PDI) de balanceamento, para ganho de peso corporal diário de $1,3 \mathrm{~kg} / \mathrm{cab}$. Em ambos os ensaios, os animais foram confinados durante 84 dias, reajustando-se as dietas a cada 28 dias, de acordo com o incremento de peso corporal, quantificado em pesagens precedidas por jejum de alimentos sólidos de $15 \mathrm{~h}$.

O concentrado foi composto por milho moído, farelo de algodão, farelo de soja, soja integral moída e núcleo mineral, sendo ajustado de acordo com as recomendações específicas de cada sistema de balanceamento. A composição das dietas iniciais empregadas em cada ensaio encontra-se na Tabela 1.

A formulação por custo minimizado, que considerou o preço de mercado atacadista à época do ajuste da ração (início do confinamento), explica o fato de as dietas iniciais de cada ensaio não serem exatamente as mesmas. 
Tabela 1 - Proporção (\% MS) dos ingredientes nas dietas iniciais para ganho de peso corporal de 1,3 kg/cab/dia, conforme a recomendação de cada tratamento avaliado

Table 1 - Proportion (\% DM) of ingredients in initial diets for body weight gain of $1.3 \mathrm{~kg} / \mathrm{head} /$ day, according to each evaluated system recommendation

\begin{tabular}{|c|c|c|c|c|c|c|}
\hline \multirow[b]{3}{*}{$\begin{array}{l}\text { Alimento } \\
\text { Feed }\end{array}$} & \multicolumn{6}{|c|}{$\begin{array}{c}\text { Tratamentos } \\
\text { Treatments } \\
\end{array}$} \\
\hline & \multicolumn{2}{|c|}{ CNCPS } & \multicolumn{2}{|c|}{ MP } & \multicolumn{2}{|c|}{ PDI } \\
\hline & $\begin{array}{l}\text { Ensaio 1 } \\
\text { Trial 1 } \\
\end{array}$ & $\begin{array}{c}\text { Ensaio } 2 \\
\text { Trial } 2 \\
\end{array}$ & $\begin{array}{c}\text { Ensaio 1 } \\
\text { Trial 1 } \\
\end{array}$ & $\begin{array}{c}\text { Ensaio } 2 \\
\text { Trial } 2 \\
\end{array}$ & $\begin{array}{l}\text { Ensaio 1 } \\
\text { Trial 1 } \\
\end{array}$ & $\begin{array}{c}\text { Ensaio 2 } \\
\text { Trial 2 } \\
\end{array}$ \\
\hline $\begin{array}{l}\text { Silagem de milho } \\
\text { Corn silage }\end{array}$ & 48,65 & 47,69 & 63,06 & 53,55 & 76,55 & 82,90 \\
\hline $\begin{array}{l}\text { Milho em grão } \\
\text { Corn grain }\end{array}$ & 31,43 & 36,61 & 19,93 & 22,24 & 8,70 & 1,28 \\
\hline $\begin{array}{l}\text { Farelo de soja } \\
\text { Soybean meal }\end{array}$ & 1,08 & 3,65 & 3,60 & 12,03 & 4,35 & 1,40 \\
\hline $\begin{array}{l}\text { Farelo de algodão } \\
\text { Cottonseed meal }\end{array}$ & 1,08 & 4,05 & 5,07 & 1,57 & 6,98 & 11,05 \\
\hline $\begin{array}{l}\text { Soja integral } \\
\text { Whole soybean }\end{array}$ & 15,14 & 6,59 & 6,64 & 9,23 & 1,45 & 1,55 \\
\hline $\begin{array}{l}\text { Premix mineral } \\
\text { Mineral mix }\end{array}$ & 1,62 & 1,41 & 1,69 & 1,38 & 1,98 & 1,82 \\
\hline Total & 100,0 & 100,0 & 100,0 & 100,0 & 100,0 & 100,0 \\
\hline $\begin{array}{l}\text { Total } \\
\mathrm{EM}(\mathrm{MJ} / \mathrm{kg} \mathrm{MS})^{2} \\
M E(M J / k g D M)\end{array}$ & 11,1 & 11,2 & 10,4 & 11,0 & 9,3 & 9,3 \\
\hline $\begin{array}{l}\mathrm{PB}(\% \mathrm{MS}) \\
C P(\% \mathrm{MS})\end{array}$ & 14,1 & 13,6 & 13,6 & 16,9 & 12,7 & 12,7 \\
\hline
\end{tabular}

1 CNCPS (Fox et al., 1992); MP (AFRC, 1993); PDI (Jarrige, 1990).

2 Estimado por meio de tabelas (NRC, 1996).

Estimated from tables of feed composition (NRC - 1996).

As sobras de alimento nos cochos foram amostradas de forma representativa, duas vezes por semana, e quantificadas, a fim de estimar o consumo. As amostras foram agrupadas em períodos de 28 dias e armazenadas em congelador. Ao final de cada período foram encaminhadas ao laboratório para análise de matéria seca, proteína bruta e energia bruta, segundo a metodologia proposta pela Association of Official Analytical Chemists (AOAC, 1995), para estimar a ingestão de nutrientes pelo animal.

Ao término do período experimental, após a pesagem final, os animais foram transportados para o matadouro-frigorífico, onde procedeu-se ao abate. No final da linha de abate, efetuou-se a pesagem das meias carcaças para obtenção do peso de carcaça quente (sem gordura perirrenal e pélvica), possibilitando o cálculo do rendimento de carcaça quente.

Seguindo as recomendações de Gomes (1966), realizou-se a análise conjunta de ambos os ensaios, sempre que a relação entre os quadrados médios residuais permaneceu abaixo de 4 , avaliando-se as médias das variáveis estudadas segundo um deli- neamento inteiramente casualizado (3 tratamentos; 10 repetições), que foram comparadas pelo teste de Duncan, a 5\% de significância. O modelo matemático utilizado foi:

$$
x_{i j}=\mu+t_{i}+\sigma_{j}+u_{i j}+e_{i j}
$$

em que $x_{i j}=$ a média observada para o ${ }_{i}$-ésimo tratamento no ${ }_{j}$-ésimo ensaio; $\mu=$ a média geral de ambos os ensaios; $t_{i}=0$ efeito do tratamento ( sistema de formulação); $s_{j}=0$ efeito do ensaio (período de realização); $u_{i j}=a$ interação entre o tratamento utilizado e o ensaio; e $e_{i j}=o$ erro experimental na parcela que recebeu o tratamento $t_{i}$ no ensaio $\sigma_{j}$.

Para análise de custos, considerou-se que a aquisição dos animais foi realizada no valor de R $\$ 38,00$ / arroba, com $55 \%$ de rendimento de carcaça quente. Ao abate, o mercado remuneraria o produtor em $\mathrm{R} \$ 42,00 /$ arroba, e o rendimento de carcaça utilizado foi a média registrada para os animais de cada tratamento. Os demais custos de produção foram considerados como complementares à fração de $85 \%$ do custo de alimentação. 


\section{Resultados e Discussão}

Em todas as variáveis analisadas, a relação entre os quadrados médios do erro experimental permaneceu abaixo de 4, e desta forma procedeu-se à avaliação conjunta dos dados. Nas diferentes avaliações, não houve efeitos de experimento, nem qualquer interação entre o experimento e a dieta utilizada. Os dados referentes ao peso inicial, ao desempenho, à ingestão absoluta e relativa de nutrientes e aos dados da carcaça estão apresentados na Tabela 2 .

$\mathrm{O}$ período de adaptação relativamente grande propiciou os resultados observados, equilibrando as parcelas experimentais quanto à condição e ao peso corporal (PC), além da redução do efeito de ganho compensatório. $\mathrm{Na}$ presente avaliação, os lotes adentraram o período experimental sem diferenças $(\mathrm{P}>0,05)$ no peso corporal, com variação relativa de apenas $2,52 \%$.

O consumo de matéria seca $(\mathrm{kg} / \mathrm{cab} / \mathrm{dia})$ diferiu $(\mathrm{P}<0,05)$ entre os tratamentos avaliados, com inferioridade do tratamento PDI em relação aos demais. Neste nível de produção, os resultados verificados na literatura consultada estão próximos dos valores obtidos no presente trabalho. Trabalhando com animais cruzados com idade média de 20 meses e peso médio de $280 \mathrm{~kg}$, Moura et al. (1975), Boin et al. (1977), Salomoni et al. (1980) e Coutinho Filho et al. (1995) verificaram consumo médio de matéria seca de $8,56 \mathrm{~kg} / \mathrm{cab} /$ dia. A marcante diferença na relação volumoso:concentrado entre as dietas fornecidas aos animais pode ter favorecido o maior consumo no caso dos tratamentos MP e CNCPS, apesar da possibilidade de ocorrência de efeito associativo negativo provocado pelo nível de concentrado nesses tratamentos. Outro fator a ser considerado seria a recomendação quantitativa do aporte de matéria seca recomendado pelo sistema PDI, que teria subestimado a capacidade de ingestão dos animais, visto que as sobras alimentares raramente foram observadas neste lote experimental.

O consumo relativo de matéria seca $(\mathrm{kg} \mathrm{MS} / 100 \mathrm{~kg}$ peso corporal) apresentou diferença significativa $(\mathrm{P}<0,05)$ entre os tratamentos avaliados, com superioridade dos tratamentos MP e CNCPS em relação ao tratamento PDI. Além do padrão estabelecido pelo consumo absoluto de matéria seca ( $\mathrm{kg} / \mathrm{cab} / \mathrm{dia})$, o caráter combinatório desta variável (consumo + peso corporal) pode ter contribuído para a obtenção do resultado, pois é provável que os menores valores

Tabela 2 - Peso corporal (PC) inicial, ganho de peso corporal (GPC), consumo de nutrientes e avaliação da carcaça de tourinhos jovens $3 / 4$ Canchim $1 / 4$ Nelore confinados, alimentados com dietas ajustadas por três diferentes sistemas de nutrição Table 2 - Initial body weight, body weight gain, nutrient intake and carcass evaluation of confined $3 / 4$ Canchim $1 / 4$ Nelore young bulls, fed with diets adjusted by three different nutritional systems

\begin{tabular}{|c|c|c|c|c|}
\hline \multirow[b]{2}{*}{$\begin{array}{l}\text { Variável } \\
\text { Variable }\end{array}$} & \multicolumn{4}{|c|}{$\begin{array}{l}\text { Tratamentos } \\
\text { Treatments } \\
\end{array}$} \\
\hline & MP & CNCPS & PDI & $\mathrm{cv} \%$ \\
\hline $\begin{array}{l}\text { Peso corporal inicial }(\mathrm{kg})^{3} \\
\text { Initial body weight }(\mathrm{kg})\end{array}$ & 421,5 & 419,0 & 410,0 & 2,52 \\
\hline $\begin{array}{l}\text { Consumo de matéria seca }(\mathrm{kg} / \mathrm{cab} / \mathrm{dia}) \\
\text { Dry matter intake }(\mathrm{kg} / \text { head/day) }\end{array}$ & $9,08^{\mathrm{a}}$ & $9,03^{\mathrm{a}}$ & $7,71^{\mathrm{b}}$ & 10,6 \\
\hline $\begin{array}{l}\text { Consumo de matéria seca }(\mathrm{kg} / 100 \mathrm{~kg} \mathrm{PC}) \\
\text { Dry matter intake }(\mathrm{kg} / 100 \mathrm{~kg} \mathrm{BW})\end{array}$ & $1,87^{\mathrm{a}}$ & $1,88^{\mathrm{a}}$ & $1,68^{b}$ & 7,5 \\
\hline $\begin{array}{l}\text { Consumo de proteína bruta }(\mathrm{kg} / 100 \mathrm{~kg} \mathrm{PC}) \\
\text { Crude protein intake }(\mathrm{kg} C P / 100 \mathrm{~kg} \mathrm{BW})\end{array}$ & $0,28^{\mathrm{a}}$ & $0,25^{\mathrm{b}}$ & $0,21^{\mathrm{c}}$ & 16,3 \\
\hline $\begin{array}{l}\text { Consumo de energia bruta }(\mathrm{MJ} / 100 \mathrm{~kg} \mathrm{PC}) \\
\text { Gross energy intake }(M J / 100 \mathrm{~kg} \mathrm{BW})\end{array}$ & $32,90^{\mathrm{a}}$ & $33,10^{\mathrm{a}}$ & $29,00^{b}$ & 11,3 \\
\hline $\begin{array}{l}\text { Ganho de peso corporal (kg/cab/dia) } \\
\text { Body weight gain (kg/head/day) }\end{array}$ & $1,51^{\mathrm{a}}$ & $1,48^{\mathrm{a}}$ & $1,13^{b}$ & 24,1 \\
\hline $\begin{array}{l}\text { Conversão alimentar }(\mathrm{kg} \mathrm{MS} / \mathrm{kg} \mathrm{GPC}) \\
\text { Feed to gain ratio }(\mathrm{kg} D M / \mathrm{kg} \mathrm{BWG})\end{array}$ & $6,24^{\mathrm{a}}$ & $6,31^{\mathrm{a}}$ & $7,02^{b}$ & 16,7 \\
\hline $\begin{array}{l}\text { Peso da carcaça quente }(\mathrm{kg}) \\
\text { Hot carcass weight }(\mathrm{kg})\end{array}$ & $322,5^{\mathrm{a}}$ & $318,3^{\mathrm{a}}$ & $295,0^{\mathrm{b}}$ & 8,6 \\
\hline $\begin{array}{l}\text { Rendimento da carcaça quente (\%PC) } \\
\text { Dressing percentage (\% body weight) }\end{array}$ & 57,00 & 56,78 & 56,58 & 4,7 \\
\hline
\end{tabular}

${ }^{1}$ CNCPS (Fox et al., 1992); MP (AFRC, 1993); PDI (Jarrige, 1990). 
absolutos de ingestão de matéria seca e ganho de peso do tratamento PDI, quando combinados, tenham acentuado as diferenças entre os tratamentos. Trabalhando com animais F1 Marchigiana/Nelore de 18 meses e $413 \mathrm{~kg}$, recebendo dieta de relação volumoso:concentrado 40:60, Junqueira et al. (1998) observaram consumo de matéria seca de $2,15 \%$, bem acima daquela proporcionada pelos tratamento CNCPS no presente trabalho, com dieta de relação volumoso:concentrado 47:53.

O efeito combinatório de peso corporal e ingestão foi ainda mais acentuado no consumo relativo de proteína bruta, com diferenças $(\mathrm{P}<0,05)$ entre os três tratamentos. Esse fato pode ser explicado pelas diferenças na concentração protéica das dietas ajustadas pelos sistemas MP e CNCPS, apesar da semelhança no consumo de matéria seca. Provavelmente em razão do menor consumo de matéria seca, o tratamento PDI também proporcionou consumo de proteína bruta inferior aos demais tratamentos, resultado que também foi intensificado pela menor concentração protéica recomendada pelo sistema. Devese ressaltar que os animais dos três tratamentos apresentaram, em média, ingestão de proteína bruta de $0,25 \%$ PC, ou seja, a ingestão de proteína foi $0,85 \%$ do ganho de peso relativo (em relação ao peso corporal), o que também foi observado por Sampaio et al. (1998).

Seguindo o perfil ditado pelo consumo de matéria seca, o consumo de energia bruta também foi diferente $(\mathrm{P}<0,05)$ entre os tratamentos avaliados. Utilizando tourinhos $3 / 4$ Canchim $1 / 4$ Nelore, com $325 \mathrm{~kg}$ e 11 meses, confinados com dietas de relação volumoso:concentrado de 60:40 compostas com silagem de milho, milho e farelo de soja, Sampaio et al. (1997) verificaram ingestão de EB de $38 \mathrm{MJ} / 100 \mathrm{~kg}$ $\mathrm{PC}$, registrando ganho de peso corporal diário de $1,34 \mathrm{~kg} / \mathrm{cab}$. É possível que mesmo com ingestão de energia bruta inferior à verificada naquele ensaio, a maior concentração energética das deitas dos tratamentos MP e CNCPS tenha resultado em maior retenção de energia e, portanto, em maior ganho de peso corporal.

A superioridade nas variáveis de consumo nos tratamentos MP e CNCPS refletiu-se de modo análogo no ganho de peso corporal, com inferioridade $(\mathrm{P}<0,05)$ nas médias apresentadas pelos animais do tratamento PDI. Cruz et al. (1996) alimentaram garrotes de diversos cruzamentos com dietas de mesma relação volumoso:concentrado e observaram ganho de peso corporal de $1,47 \mathrm{~kg} / \mathrm{cab} / \mathrm{dia}$, resultado semelhante ao do presente trabalho. A média de ganho de peso dos animais dos tratamentos avaliados permaneceu acima da média de vários outros trabalhos do gênero, que registraram ganhos médios de $1,10 \mathrm{~kg} / \mathrm{cab} / \mathrm{dia}$ (Obeid et al., 1980; Coutinho Filho et al., 1987; Sampaio et al., 1995).

As diferenças observadas para o consumo de nutrientes e o ganho de peso corporal parecem ter sido reproduzidas integralmente no resultado da comparação entre as médias de conversão alimentar. Verificou-se superioridade $(\mathrm{P}<0,05)$ dos tratamentos MP e CNCPS em relação ao PDI. Sem a interferência de ganho compensatório, são pouco freqüentes os trabalhos que registraram conversões alimentares abaixo de $6,5 \mathrm{~kg}$ MS ingerida $/ \mathrm{kg}$ ganho de peso corporal. Arrigoni (1995) e Coutinho Filho et al. (1995) observaram conversões médias de 10,0 kg MS ingerida $/ \mathrm{kg}$ ganho de peso corporal. Moura et al. (1975), Boin et al. (1977) e Chardulo et al. (1998) registraram conversões médias de 7,54; 7,08; e 7,22 kg MS ingerida/kg ganho de peso corporal, para ganhos de peso médios de 1,10; 0,91; e 1,27 kg/cab/dia, valores próximos ao tratamento PDI do presente trabalho. Magliocca et al. (1994) e Cruz et al. (1996) observaram conversões médias de 6,95 e 6,00, respectivamente, utilizando dietas, animais e níveis de produção semelhantes aos do presente trabalho, porém com peso bastante inferior $(248$ e $284 \mathrm{~kg}$, respectivamente). A variação no modo como os diferentes fatores de produção no confinamento interagem entre si pode causar expressivas diferenças no resultado final. Assim, a interação animal $\mathrm{x}$ dieta $\mathrm{x}$ meio ambiente poderá determinar resultados suficientemente alterados em sistemas de produção de características aparentemente semelhantes.

A avaliação das carcaças revelou diferenças entre os tratamentos avaliados $(\mathrm{P}<0,05)$ quanto ao peso da carcaça quente. Este resultado pode ser atribuído às diferenças observadas entre os animais dos três tratamentos durante o ensaio. Os tratamentos MP e CNCPS proporcionaram maior taxa de crescimento dos animais, o que resultou, de forma direta, em maior peso ao abate e, portanto, maior peso da carcaça.

Mesmo com significativas diferenças entre os tratamentos no peso de carcaça, o rendimento de carcaça quente foi semelhante $(\mathrm{P}>0,05)$. As médias próximas de $57 \%$ foram superiores àquelas obtidas por Steen (1995) com tourinhos cruzados Limousin $x$ 
Holandês e Belgian Blue x Holandês ganhando $1,00 \mathrm{~kg} / \mathrm{cab} / \mathrm{dia}$, que apresentaram rendimentos de carcaça de 56 e $56,3 \%$, respectivamente, para o peso de abate ajustado em $610 \mathrm{~kg}$. Na Tabela 3 estão apresentados os balanços econômicos de cada um dos tratamentos avaliados, agregando-se o efeito do rendimento de carcaça e do custo da alimentação, possibilitados pelos diferentes sistemas de ajuste.

As análises seguiram as indicações e recomendações de Lopes \& Sampaio (1999) e Nehmi et al. (2000). A interação dos resultados de consumo diário de ração, ganho de peso diário e rendimento de carcaça resultou num custo de arroba produzida de $\mathrm{R} \$ 33,99$; $\mathrm{R} \$ 39,03$ e $\mathrm{R} \$ 35,48$ para os sistemas MP, CNCPS e PDI, respectivamente. Considerando o preço de comercialização da arroba de $\mathrm{R} \$ 40,00$, observou-se que nenhum dos tratamentos prejudicou a valorização da carcaça do animal que adentrou o confinamento no início do período experimental. O maior conteúdo de concentrado na dieta recomendada pelo sistema

Tabela 3 - Análise econômica da engorda de tourinhos 3/4 Canchim $+1 / 4$ Nelore alimentados com dietas ajustadas por diferentes sistemas de nutrição 1

Table 3 - Feedlot economic analysis of 3/4 Canchim + 1/4 Nelore young bulls, fed diets adjusted by different nutritional systems

\begin{tabular}{|c|c|c|c|}
\hline \multirow[b]{2}{*}{ Item } & \multicolumn{3}{|c|}{$\begin{array}{c}\text { Tratamentos } \\
\text { Treatments }\end{array}$} \\
\hline & MP & CNCPS & PDI \\
\hline $\begin{array}{l}\text { Custo do animal } \\
\text { Animal cost }\end{array}$ & 580,00 & 580,00 & 580,00 \\
\hline $\begin{array}{l}\text { Custo da alimentação } \\
\text { Feed cost }\end{array}$ & 139,27 & 156,13 & 107,97 \\
\hline $\begin{array}{l}\text { Outros custos }(15 \%) \\
\text { Another costs }(15 \%)\end{array}$ & 24,58 & 27,55 & 19,05 \\
\hline $\begin{array}{l}\text { Subtotal } \\
\text { Subtotal }\end{array}$ & 743,84 & 763,69 & 707,03 \\
\hline $\begin{array}{l}\text { Juros sobre capital } \\
\text { Interest on capital }\end{array}$ & 11,00 & 11,30 & 10,46 \\
\hline $\begin{array}{l}\text { Total de custo } \\
\text { Total cost }\end{array}$ & 754,84 & 774,99 & 717,49 \\
\hline $\begin{array}{l}\text { Total de receita (carcaça) } \\
\text { Total income (carcass) }\end{array}$ & 903,14 & 891,24 & 826,00 \\
\hline $\begin{array}{l}\text { Lucro líquido } \\
\text { Net profit }\end{array}$ & 148,30 & 116,25 & 108,51 \\
\hline $\begin{array}{l}\text { Remuneração mensal (\% am) } \\
\text { Monthly remuneration (\%) }\end{array}$ & 6,61 & 5,11 & 5,15 \\
\hline $\begin{array}{l}1 \text { Valores expressos em } \mathrm{R} \$(\mathrm{R} \$ 2,0 \\
\text { mensal. } \\
\text { Valuesare expressed in } R \$(R \$ 2.00= \\
2 \text { CNCPS (Fox et al., 1992); MP (A }\end{array}$ & $\begin{array}{l}1.00), e x \\
0,199\end{array}$ & $\begin{array}{l}\text { monthlyr } \\
\text { DI (Jarri }\end{array}$ & $\begin{array}{l}\text { neraçãc } \\
\text { Ineration } \\
\text { 1990). }\end{array}$ \\
\hline
\end{tabular}

R. Bras. Zootec., v.31, n.1, p.157-163, 2002
CNCPS provocou aumento nos custos de produção deste tratamento, e por apenas $\mathrm{R} \$ 0,97$ o tratamento teria causado redução dos ganhos econômicos obtidos com a valorização da carcaça inicial.

Todos os sistemas de ajuste das dietas conduziram a um valor positivo de receita líquida. Observouse que, apesar dos animais serem abatidos com peso e idade superiores aos descritos por Sampaio et al. (1998), o ganho de peso corporal no confinamento foi maior, devendo ser melhor questionado qual a idade e o peso ideais de abate. Animais que se caracterizam pela precocidade devem ser explorados, a fim de proporcionarem o máximo rendimento econômico possível, para amenizar o elevado custo da fase de cria desses animais.

A remuneração do capital, um importante índice de avaliação econômica, permaneceu ao redor de $5,5 \%$ ao mês, acima da remuneração que poderia ser obtida em outras aplicações no mercado financeiro, ou ainda, em outras formas de uso e exploração da terra. Em relação à rentabilidade proporcionada pela caderneta de poupança - 0,60\% - os tratamentos proporcionaram médias de remuneração do capital quase dez vezes maior e geraram receita de aproximadamente $\mathrm{R} \$ 600,00 / \mathrm{ha} / \mathrm{ano}$.

A alta relação volumoso:concentrado da dieta recomendada pelo sistema PDI garantiu-lhe melhor taxa de remuneração mensal do que o tratamento CNCPS, apesar do gradiente de quase $31 \%$ no ganho de peso corporal. O reflexo do bom ganho de peso proporcionado pelo tratamento PDI, em virtude do baixo nível de concentrado na dieta, possibilitou rentabilidade $0,78 \%$ superior ao tratamento CNCPS, comprovando que o manejo nutricional dos animais deve agregar baixo custo e desempenho adequado.

\section{Conclusões}

As dietas ajustadas pelo CNCPS e pelo MP proporcionaram ganho de peso corporal médio superior ao previsto $(1,3 \mathrm{~kg} / \mathrm{cab} / \mathrm{dia})$ e a dieta ajustada pelo PDI não permitiu aos animais atingir a média esperada.

O desempenho dos animais alimentados com dietas ajustadas pelos sistemas CNCPS e MP foi superior ao desempenho apresentado pelos animais que consumiram dieta recomendada pelo sistema PDI.

Todos os sistemas de nutrição avaliados proporcionaram bons resultados econômicos, com rentabilidade superior a aplicações disponíveis no mercado financeiro. 


\section{Literatura Citada}

AGRICULTURAL AND FOOD RESEARCH COUNCIL AFRC. Energy and protein requirements of ruminants. Wallingford: CAB International, 1993. 159p.

ALLEONI, G.F.; BOIN, C.; TROVO, J.F.B. et al. Efeito da raça de bovinos na ingestão, digestibilidade, ganho de peso e rendimento de carcaça. Boletim de Indústria Animal, v.37, n.2, p.185-94, 1980.

ARRIGONI, M.B. Efeito da restrição alimentar sobre o desempenho, área e tipo de fibras musculares, em bovinos jovens confinados. Jaboticabal, Universidade Estadual Paulista. 1995. 73p. Tese (Doutorado em Zootecnia) Universidade Estadual Paulista, 1995.

ASSOCIATION OF OFFICIAL ANALYTICAL CHEMISTS AOAC. Animal feed. In:__. Official methods of analysis, 16.ed. Washington: 1995. v.1. p.1-30.

BOIN,C.; TROVO, J.B.F.; ALLEONI, G.F. Efeito da fonte de proteína (farelo de algodão, farelo de guar) e do nível de concentrado no desempenho de zebuínos em confinamento. Boletim de Indústria Animal, v.34, n.2, p.165-75, 1977.

CHARDULO, L.A.L.; SILVEIRA, A.C.; FURLAN, L.R. et al. Efeito da somatotropina bovina recombinante no desempenho e nas características químicas da carne de bovino. Pesquisa Agropecuária Brasileira, v.33, n.2, p.205-212, 1998.

COUTINHO FILHO, J.L.V.; PERES, R.M.; JUSTO, C.L. et al. Diferentes fontes protéicas combinadas com espiga de sorgo na engorda de mestiços Canchim em confinamento. Boletim de Indústria Animal, v.44, n.2, p.203-220, 1987.

COUTINHO FILHO, J.L.V.; SAMPAIO, A.A.M.; EZEQUIEL, J.M.B. et al. Efeito de fontes de nitrogênio e da cobertura de cocho sobre o desempenho de bovinos confinados. Revista da Sociedade Brasileira de Zootecnia, v.24, n.3, p.363$370,1995$.

CRUZ, G.M.; ALENCAR, M.M.; BARBOSA, P.F. et al. Desempenho em confinamento e características da carcaça de machos cruzados abatidos com diferentes pesos, para a produção do bovino jovem. In: REUNIÃO ANUAL DA SOCIEDADE BRASILEIRA DE ZOOTECNIA, 33., 1996, Fortaleza. Anais... Fortaleza: Sociedade Brasileira de Zootecnia, 1996. p.203-205.

FOX, D.G.; SNIFFEN, C.J.; O'CONNOR, J.D. et al. A net carbohydrate and protein system for evaluating cattle diets. III - Cattle requirements and diet adequacy. Journal of Animal Science, v.70, p.3578-3596, 1992.

GOMES, F.P. Curso de estatística experimental. 3.ed. Piracicaba: Escola Superior de Agricultura "Luiz de Queiroz", 1966. 404p.

JARRIGE, R. (Ed.). Alimentación de bovinos, ovinos y caprinos. Madri: Mundi-Prensa, 1990. 431p.

JUNQUEIRA, J.O.B.; VELLOSO, L.; FELÍCIO, P.E. Desempenho, rendimentos de carcaça e cortes de animais, machos e fêmeas, mestiços Marchigiana x Nelore, terminados em confinamento. Revista da Sociedade Brasileira de Zootecnia, v.27, n.6, p.1199-1205, 1998.

LANNA, D.P.D.; BOIN, C.; FOX, D.G. Validação do CNCPS e do NRC (1984) para estimativa dos requerimentos nutricionais e desempenho de zebuínos em crescimento. In: REUNIÃO ANUAL DA SOCIEDADE BRASILEIRA DE ZOOTECNIA, 31., 1994, Maringá. Anais.... Maringá: Sociedade Brasileira de Zootecnia, 1994. p.480.

LOPES, M.A.; SAMPAIO, A.A.M. Manual do confinador de bovinos de corte. Jaboticabal: Funep, 1999. 106p.
MAGLIOCCA, F.C.; SILVEIRA, A.C.; FURLAN, L.R. et al. Efeito da niacina e da monensina sódica no desempenho de novilhos em confinamento. Pesquisa Agropecuária Brasileira, v.29, n.6, p.983-988, 1994.

MARTIN, L.C.T. Confinamento de bovinos de corte. São Paulo: Nobel, 1987. 124p.

MORAIS, J.P.G. et al. Níveis de proteína em dietas de bagaço hidrolisado - Validação dos requerimentos estimados pelo CNCPS. In: REUNIÃO ANUAL DA SOCIEDADE BRASILEIRA DE ZOOTECNIA, 33., 1996, Fortaleza. Anais... Fortaleza: Sociedade Brasileira de Zootecnia, 1996. p.286.

MOURA, M.P.; BOIN, C.; ROCHA, G.L. Substituição parcial do farelo de algodão em níveis crescentes, por mistura de melaço-uréia para bovinos mestiços em regime de confinamento. Boletim de Indústria Animal, v.32, n.1, p.1-8, 1975.

NATIONAL RESEARCH COUNCIL - NRC. Nutrient requirement of beef cattle. Washington: National Academy Press, 1996. 242p.

NEHMI, I.M.D.; NEHMI FILHO, V.A.; FERRAZ, J.V. Anualpec - Anuário da pecuária brasileira. São Paulo: Argos, 2000. 191p.

OBEID, J.A.; GOMIDE, J.A.; SILVA, J.F.C. Efeito de níveis de uréia e do manejo da alimentação sobre o consumo alimentar e o ganho de peso de novilhos zebu em confinamento. Revista da Sociedade Brasileira de Zootecnia, v.9, n.3, p.484-493, 1980.

PERRY, T. W. Beef cattle feeding and nutrition. New York: Academic Press, 1980. 383p.

RAZOOK, A.G.; TROVO, J.B.F.; PACOLA, L.J. et al. Novas provas de ganho de peso de Sertãozinho III - Aspectos limitantes da seleção entre rebanhos de bovinos Canchim. Boletim de Indústria Animal, v.41, p.35-45, 1984.

SALOMONI, E.; Von TIESENHAUSEN, I.M.E.V.; PEREIRA, E.A. Níveis de energia na terminação de novilhos azebuados em confinamento. Pesquisa Agropecuária Brasileira, v.15, n.1, p.27-35, 1980

SAMPAIO, A.A.M.; BRITO, R.M.; VIEIRA, P.F. et al. Efeito da fonte protéica no desempenho, características da carcaça e economicidade de bezerros confinados pós-desmama. In: REUNIÃO ANUAL DA SOCIEDADE BRASILEIRA DE ZOOTECNIA, 1997, 34., Juiz de Fora. Anais... Juiz de Fora: Sociedade Brasileira de Zootecnia, 1997. p.337-339.

SAMPAIO, A.A.M.; BRITO, R.M.; VIEIRA, P.F. et al. Efeito da suplementação protéica sobre crescimento, terminação e viabilidade econômica de bezerros mestiços Canchim confinados pós-desmama. Revista da Sociedade Brasileira de Zootecnia, v.27, n.4, p.823-831, 1998.

SAMPAIO, A.A.M.; EZEQUIEL, J.M.B., CAMPOS, F.P. et al. Utilização da cama de frangos e da soja em grão na alimentação de bovinos confinados. Revista da Sociedade Brasileira de Zootecnia, v.24, n.2, p.252-260, 1995.

STEEN, R.W.J. The effect of plane of nutrition and slaughter weight on growth and food efficiency in bulls, steers and heifers of three breed crosses. Livestock Production Science, v.42, n.1, p.1-11, 1995.

VASCONCELOS, P.M.B. Guia prático para o confinador. São Paulo: Nobel, 1993. 226p. 